\title{
IFFF generation and the demise of good reading
}

\section{S. Berner \\ sberner@ecognus.com}

Two separate incidents led to the writing of this issue's column.

Incident one: I was walking my dogs one night when a couple in their mid-forties passed me by. In the two seconds during which my airwaves were overlapping theirs, I heard a fragment of a sentence, '.... and she gave me a whole heap of Web sites'.

'A whole heap of Web sites.' This was an interesting usage of English, albeit unconscious. A heap denotes a large number of things piled atop each other. Web sites are virtual, not corporeal, but they were perceived by the speaker as something one could heap: an information glut, an overload of junk data, just as junky as the food the prosperous modern world is feeding to its children. Information fries and fried fish. For the sake of elegance I will call it IFFF.

Incident two: While browsing through the shelves of a public library, I surreptitiously watched a class of 3rd grades and their teacher being introduced to the facilities. The kids had glazed, bored faces. The teacher, standing at the top of the contingent, was bawling monotonously at the top of her voice: 'This is the re-fe-rence section, boys, and here is where you find the en-cy-clo-paedias. Can anyone tell me what an en-cy-clo-paedia is, boys?' From the back came a clever response. 'It's something that comes on a CD, Miss, and has lots of pictures which you can use for your classwork, Miss!'

Gone are obviously the days when I, a young aspiring education undergraduate, would be unceremoniously ordered by the library staff to take off my high heel shoes before entering the precinct, so as not to disturb other scholars. Gone, also, are the days when we would lovingly pull out the 50 odd gilded volumes of Britannica and ensure that the African termites, so hungry for any reading material, did not get into the family heirloom. Why bother? When I was growing up, an assignment meant going into the school library and finding information on the reference shelves. Home was, for as long as I can remember, a place of shelves filled with books. Eastern Europe might not have been the best place for intellectual freedom in those days, but books were extremely cheap and this is where I read all the world literature classics. On the other hand, if I want to find a book by the likes of Kazantakis, or Proust or Balzac in Australia today, I need to dig deep - both in the shelves and in my pocket - at a place aptly named The Archives, where they rub shoulders with vanilla romance and gory horror books.

Has the glut of data in electronic format killed our ability to enjoy book (but also newspaper and magazine) reading? Has Internet 'literacy' led to book 'illiteracy'? How does the perception of this Internet generation differ from ours when it comes to savouring words, respecting the work that goes into producing them and absorbing/retaining information from 
flickers on a screen that are here today and gone tomorrow? And what changes when knowledge becomes demoted from a 'quest' to a 'search': does it lose some of its value which was inherent in it because of its scarcity and the effort that needed to be exerted in obtaining it, or does it retain that value?

At the risk of repeating this ad nauseam, reading any long text off-line is, up to date, ergonomically impossible and opthalmologically detrimental. There is no lack of books in electronic formats - some best world literature is on Gutenberg for free, and there are others who provide this service for a fee (Questia being one). However, one will eventually have to print the material (so much for saving trees and abiding by copyright) to be able to read it at any length. Unless you are very determined (few are), this will mean that only snippets will be read, creating a 'cut-and-paste' mentality in the younger generation so totally dependent on the information (or otherwise) provided on the Internet - too overwhelming, and yet too patchy.

Children are visual, and so the Internet feeds excellently into their modus operandi. Unfortunately, language, reading and especially linear reading use a totally different set of brain wiring to that used by visual perception. Erica Wagner, a publisher at the Australian Allen and Unwin, says: '[Books] are a private experience, and you enter into a world imaginatively that is different to sitting in front of a computer where it's all there in bright colours.' Children are not born readers; it takes discipline, patience and diligence to learn how to enjoy reading. It is also natural for humans to go down paths of least resistance, and if information is available in an IFFF format, why should one bother about wholesome quality, especially if the majority of people surrounding the child do not have a clue about how to estimate that quality in the first place. Wagner seems to be seeing a compromise, 'Children ... are used to using the Internet and darting here and there, so we (Allen \& Unwin) are publishing quite a lot of junior novels with lots of illustrations where the cartoon content is read within the story' (Haywood 2004).

I do grant electronic formats the benefit of being more compact. After decades of collecting books and not being able to find a Books Anonymous organization to cure me, nor a magic wand that would expand the available wall space, I am faced with two options: convert them into electronic formats or buy a larger house. I think the first is cheaper, and I have been storing most of my work materials on CDs; but as for books, I am open to property offers. Being more compact, it also means that I can share them with friends overseas much faster and cheaper than I would if they were in paper format. I have yet to come across any of my friends, however, who would prefer me to send them an e-book rather than the hard copy.

One cannot attempt to look at all the possible implications of the 'online reading' trend, or the lack of it, in an editorial column. But apart from patchiness of information, the developments of new forms of language usage due mainly to online communication also beg the question: What kind of literature will the world have in the coming 100 years? With the use of emoticons and abbreviations, and a lingua electronica that bridges world languages creating a special class of the e-savvy cosmopolitan young, will we be seeing the slow demise of language as we have known it? With the great ease with which we can now verbally and visually communicate online (chat software coupled with camcorders and cable Internet is just the tip of an iceberg) will we slowly move away from written language and back to verbal communication? How will that, if it happens, affect the creation and dissemination, not to mention storage, of information? Oral societies have very long memories, whereas the modern world Internet user has an attention span of about 15 seconds.

While I started this article with the intention of finding at least a few answers to my questions, I ended up merely sharing them with you with the sincere hope that the thread generates further discussion. Before I wrap up, I would like to leave you with a comment 
from a UK book lover: 'Books have the virtue of being tested. If you pick a text off the shelf you can be confident that no one would have published the thing if it was rubbish. If you look for information on the Internet, especially scientific papers, you end up with endless, untrusted papers written by any old quack with a computer' (BBC 2000). I am not sure if I totally agree with the trust aspect, though. But if the Internet is to stop being IFFFy, then we surely need to think about what skills we are leaving the coming generations of readers.

\section{References}

Haywood, W. 2004. Books of the future. In Connections (48). Available WWW: http://www.curriculum.edu.au/scis/connections/cnetw04/48future.htm

BBC. 2000. Is there a future for public libraries? Available WWW: http://news.bbc.co.uk/1/hi/talking_point/749030.stm

\section{About the author}

Sam Berner (B.Ed., Dipl. LIS, Postgraduate Diploma in Information Management) is a principal of the company ECognus (Brisbane, Australia). She is a knowledge management consultant, assisting small to medium enterprises to benefit the most from their intellectual assets. ECognus also provides services in the area of tailored software applications and the digitization of business processes.

\section{Disclaimer}

Articles published in SAJIM are the opinions of the authors and do not necessarily reflect the opinion of the Editor, Board, Publisher, Webmaster or the Rand Afrikaans University. The user hereby waives any claim he/she/they may have or acquire against the publisher, its suppliers, licensees and sub licensees and indemnifies all said persons from any claims, lawsuits, proceedings, costs, special, incidental, consequential or indirect damages, including damages for loss of profits, loss of business or downtime arising out of or relating to the user's use of the Website.

ISSN 1560-683X

Published by InterWord Communications for Department of Information and Knowledge Management, University of Johannesburg 